\title{
Determinant of Family Harmony with Autism Spectrum Disorder (ASD): A Systematic Review
}

\author{
Nailul Fauziah ${ }^{1,2}$, Nurul Hartini ${ }^{3}$, Wiwin Hendriani ${ }^{4}$, Fendy Suhariadi ${ }^{5}$ \\ \{nailulburhan@gmail.com ${ }^{1}$ \} \\ Universitas Airlangga, Indonesia ${ }^{1,3,4,5}$ \\ Universitas Diponegoro, Indonesia ${ }^{2}$
}

\begin{abstract}
Family harmony refers to a condition or perception that family members have comfortable and pleasant interactions. However, there in two contradictive perception, about the influence of children with ASD in family harmony, problems may arise or can increase the cohesiveness and greater empathy. The present study aims poses the following research questions: What are the factors or determinants of family harmony with autistic children? To answer these questions, we apply a systematic review method. Search strategy in this study employs eight electronic databases resources, namely: Garuda Ristekdikti, Sage, Science Direct, Google Scholar, Springer link, ERIC, Emerald and psych INFO. The data analyzed are from 22 articles that meet certain eligibility criteria. Results of the analysis show the following determinants of family with ASD are: (1) optimism, (2) social support, (3) coping, (4) role division, and (5) positive beliefs. Although harmony is particularly important in families with ASD children, research on this specific context has not been published.
\end{abstract}

Keywords: Determinant, Family Harmony, Autism Spectrum Disorder (ASD), Systematic Review

\section{Introduction}

Autism spectrum disorder (ASD) is a developmental condition that occurs in children. This disorder, which is experienced since birth or infancy, makes a person unable to communicate normally or form normal social relations [1]. The symptoms of autism appear before the child reaches the age of three years [2]. Children with ASD experience cognitive, affective, and behavioral disorders. The most typical and dominant disorder are related to communication and social interaction. Children with ASD experience difficulties in understanding others and expressing their feelings to them. Biological or physical disorders are also experienced by these children. Many parents complain about sleep disorders experienced by ASD children, how easily they get sick, and how they encounter behavioral and concentration problems when they eat the wrong food. Typically, ASD children have special dietary requirements to support their development.

The number of children with autism increases from year to year. Based on data from the World Health Organization (WHO), the prevalence of autism in Indonesia has increased significantly from 1 per 1,000 population to 8 per 1,000 population, surpassing the global average of 6 per 1,000 population. In 2009, the number of children with autism reached 150,000-200,000. Other data in 2015 estimate that more than 12,800 children in Indonesia have autism and 134,000 have autism spectrum (klinikautisme.com). Other data in 2018 
predicted that 12.4 million people in Indonesia would be affected by autism, with an increase of 500 people per year [3].

Parents and siblings of ASD children experience problems and disturbances because they share the same environment with the children. They experience many problems in caring for ASD children, ranging from communication, confusion in understanding the children's wishes, anxiety and stress in caring, depression, and financial problems resulting from high cost of therapy and education for ASD children. Another problem that affects family harmony is other people's opinion that having ASD children is a punishment. Conflict may be triggered by the parents' inability to understand the children's wishes, discuss the children's condition, anxiety, and difficulty communicating with ASD children, being ashamed about the children's condition, having no support from the extended family, being ridiculed by others, and jealousy of siblings as parents focus more of their attention on the ASD children. According to Cohen and Bolton, having children with autism can cause stress, which greatly affects a marital relationship. The marriage relationship may experience conflict, and even separation and divorce [4].

Apparently, some research on families with ASD children also found that such a situation increases cohesiveness in the family [5]. Centering autism within the family: A qualitative approach to autism and the family found that having an autistic child is an adversity, but this experience can lead to a "rich" and meaningful life. This experience prompts family members to survive the "shame" of having a "different" child, and enables them to develop patience in observing the development of a different child. They also feel satisfied when progressive development occurs, and are aware that the development of an autistic child is not as natural as experienced by other children All forms of constrains lead family members to feel "priceless" and experience a more meaningful life. God does not give parents special children because they are special; but they are special because they are given special children.

O'Brien [6] showed a need for balance and harmony in a family that is caring for children with autism, as well as the need to use all internal and external abilities to interpret situations. In line with research findings, sometimes families also need help from healthcare workers and other mental health professionals to identify the right coping strategies to ensure a meaningful family life

Shiver (2019) compared empathy and understanding the perceptions of others in children who have ASD siblings compared with those who do not; the study found that children with ASD siblings have higher empathy scores and understanding abilities because they are forced to understand the condition of their siblings compared with children who do not have ASD siblings.

Javadian [7] examined the differences in adaptation and cohesion in families with and without ASD children, and found that adaptability, cohesiveness, and communion in families with ASD children is higher than those in families that do not have such children.

These findings show that having ASD children forces various positive attributes to appear in family members, such as toughness in facing challenges, patience, coping, empathy, adaptation, cohesiveness, ability to survive under environmental pressure, and meaningfulness. But research on family harmony, especially those with ASD children, is still very little published [8]. These two conflicting research results have to be studied further so that the following systematic research issues can be addressed: what factors cause the family to be more harmonious despite having ASD children? 


\section{Method}

This study uses a systematic review method called PRISMA-P (Preferred Reporting Items for Systematic Reviews [9]) as a reference for the preparation of the article. The PRISMA-P 2015 checklist consists of 27 items that must be met so that a study can be described as systematic. These 27 items are used as a guide in developing the introductory chapter, research method, results, and conclusions [9]. Certain preparations and sequences in compiling the literature review must be met to achieve a systematic review process. PRISMA helps researchers review the literature in a manner that meets scientific requirements, is carried out correctly, well documented, and consistent throughout the research process [9].

\subsection{Data Search Strategy}

To address the aforementioned research questions, we conducted a systematic literature review of the works focused on the harmony of families that have children with ASD and other special needs. The inclusion criteria are quantitative and qualitative studies, books, and book sections that focus on family harmony as key variables or subject areas. The search is limited to open access works published from January 1, 1980 to December 31, 2019 because the 1980s represented the decade of substantial research on family harmony, particularly the theory of family harmony were conducted and published by Moose [10]. Google Scholar and Garuda Dikti, which uses Indonesian-language keywords, were also used to find articles about family harmony and children with ASD and special needs in Indonesia. The full search strategy is presented in Table 1. Studies that did not meet the inclusion criteria were excluded. Features that are parts of a book are also included in this literature review. Screening has been conducted to select journals with titles and abstracts that fit the inclusion criteria. Then, the researcher selects eligible articles that can be fully accessed.

Table 1. Search terms and filters for each database

\begin{tabular}{|l|c|c|}
\hline \multicolumn{1}{|c|}{ Database } & Search Terms & Results \\
\hline Garuda Menristedikti & [family harmony] and [autism/ASD] & 24 \\
\hline Google Scholar & [family Harmony] and [autism/ASD] & 410 \\
\hline Emerald & [family harmony] and [autism/ASD] & 34 \\
\hline Sage & [family harmony] and [autism/ASD] & 678 \\
\hline Science Direct & [family harmony] and [autism/ASD] & 373 \\
\hline Springer Link & [family harmony] and [autism/ASD] & 675 \\
\hline ProQuest & [family harmony] and [autism/ASD] & 288 \\
\hline JSTOR & [family harmony] and [autism/ASD] & 295 \\
\hline
\end{tabular}

\subsection{Data Extraction}

Data extracted from the articles include author's name, year, journal name, city, number of samples, methods, theory, research design, measurement tools used, and results.

\subsection{Inclusion Criteria}

To limit the risk of bias from the analyzed data, we select the articles whose title and contents focus on the harmony of families with ASD children, not including family support, 
family happiness, and others. Thus, the articles clearly state the theory of family harmony with ASD children. The measuring instrument used also measures family harmony to avoid confusion with other similar variables. However, due to the limitations of the articles specifically about the harmony of families with ASD children, we restrict our references to studies that cover aspects of harmony such as cohesiveness, empathy, and togetherness at the family level and not only from the point of view of the father or mother.

\subsection{Methodological Quality Review}

To limit the risk of bias from the analyzed data, we select the articles whose title and contents focus on the harmony of families with ASD children, not including family support, family happiness, and others. Thus, the articles clearly state the theory of family harmony with ASD children. The measuring instrument used also measures family harmony to avoid confusion with other similar variables. However, due to the limitations of the articles specifically about the harmony of families with ASD children, we restrict our references to studies that cover aspects of harmony such as cohesiveness, empathy, and togetherness at the family level and not only from the point of view of the father or mother.

\subsection{Data Analysis}

After data extraction, data analysis is conducted using descriptive narrative analysis techniques. The review is conducted to answer the research questions. Researchers aim to examine various determinants of family harmony with ASD children, including studies developed in Indonesia.

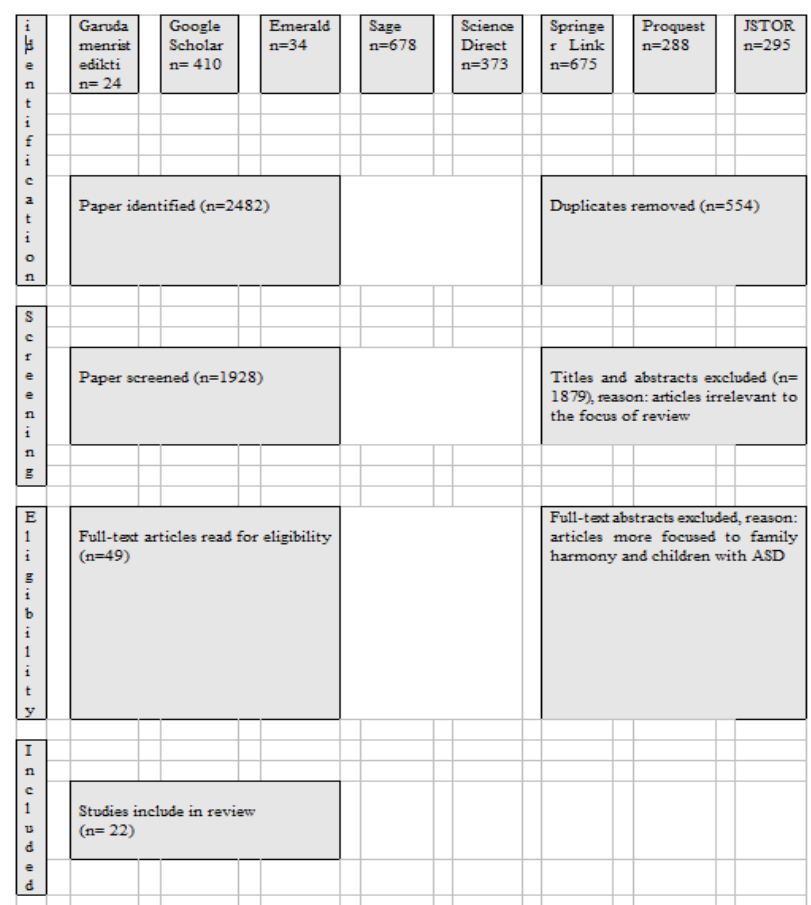

Fig. 1. Diagram of article selection process using PRISMA. 
An initial search of the eight databases yielded 2,482 articles, among which 554 were duplicated and 1 that was unrelated to the purpose of this study was excluded. A total of 458 articles were then re-filtered based on the focus of the literature review. Further review of full text eliminated as many as 402 articles. Finally, 12 articles were included in the literature review.

\section{Result}

Based on a review of research articles on family harmony with ASD children, the following results are presented. First, based on the first review conducted on family harmony in various settings, overall research defines the domain perceptions of family members about family conditions, that is feeling whole, safe, and comfortable, with several key determinants: commitment, appreciation, affection, reduced conflict, and togetherness. The different settings bring up some additional determinants of family harmony. Second, an article that specifically discusses the harmony of families with ASD children has not been found, so the article selection and discussion covers aspects of harmony that have aspects related to family harmony. A total of 12 articles were found.

Table 2. shows the results of research on family harmony and ASD

\begin{tabular}{|c|c|c|}
\hline Author and Year & Title of Study & $\begin{array}{c}\text { Reason for Family } \\
\text { Harmony }\end{array}$ \\
\hline $\begin{array}{l}\text { Lopez, Reed, and } \\
\text { Magaña [11] }\end{array}$ & $\begin{array}{l}\text { Associations among family burden, } \\
\text { optimism, services received, and } \\
\text { unmet needs within families of } \\
\text { children with ASD }\end{array}$ & Optimism \\
\hline $\begin{array}{l}\text { Hoogsteen and Woodgate } \\
{[5]}\end{array}$ & & $\begin{array}{l}\text { Division of roles in } \\
\text { the family }\end{array}$ \\
\hline $\begin{array}{l}\text { Maria Laksmi Ananta } \\
\text { Sari [12] }\end{array}$ & $\begin{array}{l}\text { Growing together in stress (stress- } \\
\text { related growth in those with autistic } \\
\text { children) }\end{array}$ & \\
\hline $\begin{array}{l}\text { Jocelyn Bessette Gorlin } \\
\text { et al. [13] }\end{array}$ & $\begin{array}{l}\text { Severe childhood autism: the family } \\
\text { lived experience }\end{array}$ & Family support \\
\hline $\begin{array}{l}\text { Richard P. Hastings and } \\
\text { Emma Johnson [14] }\end{array}$ & $\begin{array}{l}\text { Stress in UK families conducting } \\
\text { intensive home-based behavioral } \\
\text { intervention for their young child } \\
\text { with autism }\end{array}$ & $\begin{array}{l}\text { Positive beliefs, } \\
\text { which reduce } \\
\text { pessimism }\end{array}$ \\
\hline $\begin{array}{l}\ldots \text { Baker and } \\
\ldots \text { Blacher }[15]\end{array}$ & $\begin{array}{l}\text { Preschool children with and without } \\
\text { developmental delay: behavior } \\
\text { problems, parents' optimism and } \\
\text { well-being }\end{array}$ & $\begin{array}{l}\text { Optimism improves } \\
\text { the mother's well- } \\
\text { being, thereby } \\
\text { resulting in a happy }\end{array}$ \\
\hline
\end{tabular}




\begin{tabular}{|c|l|c|}
\hline $\begin{array}{c}\text { Tali Heiman and Ornit } \\
\text { Berger [16] }\end{array}$ & $\begin{array}{l}\text { Parents of children with Asperger's } \\
\text { syndrome or with learning } \\
\text { disabilities: Family environment and } \\
\text { social support }\end{array}$ & Optimism \\
\hline Barara [17] & & Social support \\
\hline Faisal Malik (2018) & $\begin{array}{l}\text { Marriage satisfaction of couples who } \\
\text { have autistic children }\end{array}$ & $\begin{array}{c}\text { SWB, conflict } \\
\text { resolution }\end{array}$ \\
\hline Gorlin [13] & $\begin{array}{l}\text { Severe childhood autism: the family } \\
\text { lived experience }\end{array}$ & $\begin{array}{c}\text { Social support } \\
\text { (family or non- } \\
\text { family) and } \\
\text { compassion among } \\
\text { family members }\end{array}$ \\
\hline Kashdan Todd [18] & $\begin{array}{l}\text { Hope and optimism as human } \\
\text { strengths in parents of children with } \\
\text { externalizing disorders; stress is in } \\
\text { the eye of the beholder }\end{array}$ & \begin{tabular}{c} 
Hope and optimism \\
\hline
\end{tabular} \\
\hline
\end{tabular}

\section{Discussion}

Lopez et al [11] conducted a qualitative study that used in-depth interviews and found that optimism greatly affects the ability of a family to remain harmonious, keeps families motivated, and tries to establish good relationships with family through the division of roles, and by overcoming conflicts and existing challenges, so that family members are motivated to establish good relationships among themselves.

Hoogsteen \& Woodgate [5] conducted a study that was almost similar to that of Lopez et al. [11] they found that the division of roles enabled a good relationship among family members and unintentionally brought them closer to one another

Qualitative research by Maria Laksmi Ananta Sari also found that families with ASD children have two choices: surrender or grow. Family determinants will grow in challenges. Families more have character/identity from this case. Strong identity, pressure, impact pressure, spirituality, and social support (community, etc.) [12].

Gorlin [13] found that family conditions are good when the family obtains social support even from people who are emotionally close to them and not blood relatives. The social support makes the family feel that they are not alone, thereby resulting in happiness and harmony.

Hasting [14], by studying the level of family stress in the United Kingdom in caring for children with home-based interventions, found that psychological factors have more influence on family stress than demographic factors. Passive coping abilities and trust enables the family to overcome problems (self-efficacy). Pessimism causes further stress, and conversely, 
positive coping abilities enable families to overcome problems and establish harmonious relations among members [14].

Baker [19] found that optimism plays an important role by promoting happiness and a harmonious relationship among family members. Heiman and Berger [16] conducted a quantitative study, which found that optimism is the essence of harmony in a family.

Barara [17] showed that social support obtained by family members enabled them to feel strong and establish a harmonious relationship. Malik [20] found that conflict resolution is important in a family that has autistic children. When the family can overcome the conflicts that they experience, then they can survive and achieve harmony.

Kashdan [18] showed that optimism is influenced by several factors, such as strong relations between parents, adaptability of individuals (e.g., self-esteem), and familial functioning.

This description above, are explained about research result from this literature study. Factors can be influence family harmony was found, however article selection and discussion covers aspects of harmony that have aspects related to family harmony. Some of the articles above do not show the variable of family harmony directly in their search, but try to relate some of the determinants found with the theme of family and autism and reveal aspects of family harmony. Aspects of family harmony are at least expressed by the following three figures, namely De Frain \& Stinnet [21] and Kovikondala [22].

The next research until it emerged as a reference book about families was and De Frain \& Stinnet's [21] research on strength family. According to Mace strength family is one of the factors that influence the formation of family harmony. Strength family is the relationship characteristics that affect emotional health and family well-being. Families that claim to be strong families can be expressed between family members by loving each other, living in happiness and harmony.

Theories about family harmony De Frain \& Stinnet [21] describe aspects of family harmony as follows: commitment; appreciation and affection; positive communication; time together; spiritual wellbeing; and the ability to cope with stress and crisis.

Creating religious life. This is important because in religion, there are moral values and life ethics. Based on several studies, it is found that non-religious families with low commitment or no religious values tend to have conflicts and disagreements within the family, with an atmosphere like this, the child will feel uneasy at home and most likely will look for another environment who can receive them better.

Having time with family. Families should always provide time to be with their family members, whether it's just gathering, eating together, accompanying children to play, and even listening to problems and complaints of children. In this togetherness children will feel themselves needed and cared for by their parents, so that they will feel at home.

Having good communication between family members. Teenagers will feel safe if their parents look harmonious, because harmony will provide a sense of security and peace for children. Good communication within the family will also be able to help teens to solve the problems they face outside the home, in this case besides acting as parents, mothers and fathers also have to act as friends, so that children have more freedom and more open in conveying all their problems.

Mutual respect among family members. The family provides a place for each family member to appreciate the changes that occur and teach children the skills to interact as early as possible with bigger environment.

The quality and quantity of conflict is minimal. If there are frequent disputes and quarrels in the family then the atmosphere in the family is no longer pleasant. In a harmonious family, 
each family member tries to solve problems with a cool head and seeks the best solution for each problem.

There is a close relationship or bond between family members. A close relationship between family members also determines the harmony of a family. If in a family, does not exist a close relationship between family members, there will no longer be a sense of belonging and the sense of togetherness. This close relationship between family members can be realized with togetherness, good communication between family members, as well as mutual respect.

Family strength theory didn't explain about how dynamics or fluctuation for family harmony. That family harmony is dynamic, not permanent and keeps changing throughout the course of life in the family with all the problems and conflicts faced as well as with many factors that influence, there must be an occasional time when family harmony rises and there is a time to fall or be stable.

Lam et al. [23] conducted qualitative research on Chinese family harmony, obtaining the following results: family harmony consists of four components, such as: communication, appreciation, the least amount of conflict that arises, as well as time spent with the family. Reducing conflict will develop other valuable abilities in the family, parenting style and financial difficulties are also a source of conflict.

In research Lam et al [23] the concept of family harmony, some determinants that affect family harmony begin to be explained, but do not comprehensively explain when family harmony is at the most harmonious position and what factors influence and vice versa when what harmony in a family is at that point lowest and what factors influence. Neither in the study described by Kovikondala [22].

Family Harmony's aspect from Kovikondala [22] are commitment, appreciation and affection, positive communication, time together, spiritual well-being, ability to deal with stress and crisis and family identity (indigenous determinants). Kovikundala's research made a model with the name FHS (Family Harmony Scale) which is still being developed for its scale making.

Another result is the finding that context greatly influences the determinants that affect family harmony. Stinnet and De Frain's [13] research has different determinants from the research of Lam et.al [23] due to different research contexts.

\section{Conclusion}

Based on the research that has been analyzed, the following determinants distinguish between harmonious and disharmonious families with autistic children: (1) optimism, (2) social support, (3) coping, (4) role division, and (5) positive beliefs. We can also obtain the following conclusions: (1) Although the analyzed studies do not directly explain that some of these determinants make a harmonious family, the process of achieving harmony can go through several stages that involve specific aspects. Further studies can be conducted based on which factors are most dominant in determining harmony in families with ASD children although the determinants do not directly lead to harmony in the family.

Based on the preceding findings, further research is necessary on family harmony through quantitative and qualitative methods. This literature review confirms that optimism, social support, coping, division of roles, and positive beliefs are the dominant factors that influence the development of harmony in families with ASD children. 


\section{Suggestion}

This research can be developed by another researcher by continues research with quantitate and qualitative research. Quantitative research with develop specific measurement of family harmony with Autism Spectrum Disorder (ASD) in other context. And qualitative research with other approach to make clearly about dynamics or fluctuation of family harmony with Autism Spectrum Disorder (ASD).

\section{Acknowledgment}

The author is grateful to the Doctoral Study Program of the Faculty of Psychology at Airlangga University, as well as the Faculty of Psychology at Diponegoro University. Gratitude is also extended to the Indonesian Education Fund Management Institute (LPDP), which provided financial support that enabled the author to continue his doctoral studies at the Faculty of Psychology, Airlangga University, Surabaya.

\section{References}

[1] D. A. Mash, E.J., \& Wolfe, Disorders of childhood and adolescence. 2013.

[2] R. Sutadi, "International Autism Day. Ministry of Woman Empowerment and Child Protection, 04.02,"https://www.kemenpppa.go.id/index.php/page/read/31/1682/hari-peduli-autismesedunia-kenali-gejalanya-pahami-keadaannya, 2018. .

[3] A. Tamba, "Trends in Autism Sufferers Increase," Jakarta. National Daily., 2018. .

[4] S. Mehvar, T. Filatova, I. Syukri, A. Dastgheib, and R. Ranasinghe, "Developing a framework to quantify potential Sea level rise-driven environmental losses: A case study in Semarang coastal area, Indonesia," Environ. Sci. Policy, vol. 89, no. February, pp. 216-230, 2018, doi: 10.1016/j.envsci.2018.06.019.

[5] L. Hoogsteen and R. L. Woodgate, "Centering autism within the family: A qualitative approach to autism and the family," J. Pediatr. Nurs., vol. 28, no. 2, pp. 135-140, 2013.

[6] S. O'Brien, "Families of adolescents with autism: Facing the future," J. Pediatr. Nurs., vol. 31, no. 2, pp. 204-213, 2016.

[7] R. Javadian, "A comparative study of adaptability and cohesion in families with and without a disabled child," Procedia-Social Behav. Sci., vol. 30, pp. 2625-2630, 2011.

[8] N. Fauziah, "The Concept of Family's Harmony in Multiple Cultural Settings, What About the Family Harmony With Autism Children in Indonesia? A Literature Study," Fam. J., p. $1066480720904027,2020$.

[9] D. Moher et al., "Preferred reporting items for systematic review and meta-analysis protocols (PRISMA-P) 2015 statement," Syst. Rev., vol. 4, no. 1, p. 1, 2015.

[10] R. H. Moos and B. S. Moos, "Family Environment Scale. 2d ed. Palo Alto." CA: Consulting Psychologists Press, Inc, 1986.

[11] K. Lopez, J. Reed, and S. Magaña, "Associations among family burden, optimism, services received and unmet need within families of children with ASD," Child. Youth Serv. Rev., vol. 98, pp. 105-112, 2019.

[12] M. L. . Anantasari, (Growing together in stress (stress related growth) for those who have ASDconverted children, n.d.). Yogyakarta: Sanata Dharma University, 2016.

[13] J. B. Gorlin, C. P. McAlpine, A. Garwick, and E. Wieling, "Severe childhood autism: The family lived experience," J. Pediatr. Nurs., vol. 31, no. 6, pp. 580-597, 2016.

[14] R. P. Hastings and E. Johnson, "Stress in UK families conducting intensive home-based 
behavioral intervention for their young child with autism," J. Autism Dev. Disord., vol. 31, no. 3, pp. 327-336, 2001.

[15] B. L. Baker, J. Blacher, and M. B. Olsson, "Preschool children with and without developmental delay: behaviour problems, parents' optimism and well-being," J. Intellect. Disabil. Res., vol. 49, no. 8, pp. 575-590, 2005.

[16] T. Heiman and O. Berger, "Parents of children with Asperger syndrome or with learning disabilities: Family environment and social support," Res. Dev. Disabil., vol. 29, no. 4, pp. 289 300,2008

[17] I. Barara, "Marriage satisfaction for parents who have autistic children in Nanggroe Aceh Darussalam," University of North Sumatra, 2009.

[18] T. B. Kashdan et al., "Hope and optimism as human strengths in parents of children with externalizing disorders: Stress is in the eye of the beholder," J. Soc. Clin. Psychol., vol. 21, no. 4, pp. 441-468, 2002.

[19] D. E. Berkell, Autism: Identification education and treatment. 1992.

[20] F. Malik, "Relationship subjective well being and conflict resolution of marriage satisfaction."

[21] jr. (ed). Defrain, J., \& Stinnett. Family strength in. j.j ponzetti, international encyclopedia of marriage and family. New York: The Gale Group Inc, 2003.

[22] J. H. Wortmann et al., "Psychometric analysis of the PTSD Checklist-5 (PCL-5) among treatment-seeking military service members.," Psychol. Assess., vol. 28, no. 11, p. 1392, 2016.

[23] W. W. T. Lam et al., "Perspectives on family health, happiness and harmony (3H) among Hong Kong Chinese people: a qualitative study," Health Educ. Res., vol. 27, no. 5, pp. 767-779, 2012. 